\title{
Influence of coffee consumption on bone mineral density in postmenopausal women with estrogen deficiency in menstrual history
}

\author{
Amila Kapetanović1* , Dijana Avdić \\ ${ }^{1}$ Medical Rehabilitation Center Fojnica, Fojnica, Bosnia and Herzegovina, ${ }^{2} \mathrm{Clinic}$ for orthopedics and traumatology, \\ University Clinical Center of Sarajevo, Sarajevo, Bosnia and Herzegovina
}

\begin{abstract}
Introduction: Complex etiology of osteoporosis include genetic, hormonal, environmental and nutritional factors. The aim of this study was to examine influence of coffee consumption on bone mineral density in postmenopausal women with estrogen deficiency in menstrual history.

Methods: This prospective study included 100 postmenopausal women, aged 50-65 years living in Sarajevo area, with estrogen deficiency in their menstrual history. The controlled clinical trials were conducted. Two groups were formed (based on bone mineral density values). The examination group included 50 women who had osteoporosis, while the control group included 50 women without osteoporosis (osteopenia, normal bone mineral density). The lumbar spine and proximal femur bone mineral density was measured by Dual-Energy X-ray Absorptiometry using Hologic QDR-4000 scanner. Coffee drinking habits were assessed for each subject.
\end{abstract}

Results: The average daily intake of coffee in women with estrogen deficiency in menstrual history was at $267.6 \mathrm{ml}$ in the examination group and in the control group $111.6 \mathrm{ml}$. The difference in the average daily intake of coffee between the two groups was statistically significant $(p<0.001)$. There was registered significant correlation between intake of coffee and bone mineral density in examination $(p<0.01)$ and in control group $(p<0.05)$.

Conclusion: This study indicates that coffee consumption is a risk factor for osteoporosis in postmenopausal women, aged 50-65 years living in Sarajevo area, with estrogen deficiency in their menstrual history. It was shown that the effects of coffee on bone mineral density are dose-dependent.

Keywords: coffee consumption; osteoporosis

\footnotetext{
*Corresponding author: Amila Kapetanović,

Medical Rehabilitation Center Fojnica, Fojnica, Bosnia and Herzegovina

E-mail nermin1a@bih.net.ba
}

Submitted August 32014 / Accepted September 92014

\section{INTRODUCTION}

The female reproductive system plays a major role in regulating the acquisition and loss of bone by the skeleton from menarche through senescence (1). Longer exposure to estrogen, either through natural menstruation or postmenopausal Estrogen Replacement Therapy, have protective effects 
on bone mineral density (2). The loss of ovarian function, whether premature or not, lead to an increased risk of bone mineral loss and developing of osteoporosis because of the lengthened time of exposure to reduced estrogen (3).

Osteoporosis has a complex etiology and is considered as a multifactorial polygenic disease in which genetic determinants are modulated by hormonal, environmental, and nutritional factors (4). Determination of osteoporosis risk factors related to habits (lifestyle) is important for both, prevention as well as disease treatment, as these factors can be modified. Caffeine for years is under discussion, whether has positive whether adverse impact on health (5). Opinions about impact of coffee consumption on bone metabolism are still controversial. Study of Hasling C. et al. found that a coffee intake in excess of $1000 \mathrm{ml}$ could induce an extra calcium loss of $1.6 \mathrm{mmol}$ calcium/d, whereas intakes of 1-2 cups of coffee per day would have little impact on calcium balance in postmenopausal osteoporotic women, age 48 to 77 years, with postmenopausal crush fracture (6). Barger-Lux MJet Heaney RP analyzed data from 560 calcium balance studies carried out on women aged from 34.8 to 69.3 years. The authors found a caffeine relationship such that for every $177.5 \mathrm{ml}$ serving of caffeine-containing coffee, calcium balance was more negative by $0.114 \mathrm{mmol} /$ day $(4.6 \mathrm{mg} /$ day $)$. There was no evidence that the putative caffeine effect is confined to, or is greater among, subjects with low calcium intakes or those who are older or estrogen-deprived (7). Heaney RP found no evidence that caffeine has any harmful effect on bone status or on the calcium economy in individuals who ingest the currently recommended daily allowances of calcium (8). Study of Lacerda et al. examining effects of coffee on bone metabolism of mousses, indicated that coffee consumption has an effect on metabolism of calcium (including increased level of calcium in urine and plasma, decreased bone mineral density and lower bone volume) (9). Study of Sakamoto et al haven't found that coffee stimulates loss of bone tissue in mousses (10). That intakes of caffeine in amounts $>300 \mathrm{mg} / \mathrm{d}$ accelerate bone loss at the spine in elderly postmenopausal women and that women with the genetic variant of vitamin $\mathrm{D}$ receptor appear to be at a greater risk for this deleterious effect of caffeine on bone was indicated in the study of Rapuri PB et al. (11). Direct negative effects of caffeine on osteoblastic cells (deleterious effect on the osteoblasts viability) was suggested in the study of Tsuang YH et al. (12). Goto et al. have found that plasma concentration sex hormone-binding globulin (SHBG) that binds estrogen (lower bioavailability of sex hormones) was higher in women who consumed four or more cups than women who did not consume coffee (13). The results of Wedick NM et al. study do not indicate a consistent effect of caffeinated coffee consumption on SHBG in men or women (14).

The data about the effects of coffee on bone are inconsistent. The aim of this study was to examine influence of coffee consumption on bone mineral density in postmenopausal women with estrogen deficiency in menstrual history.

\section{METHODS}

\section{Study design}

This prospective study included 100 postmenopausal women, aged 50-65 years living in Sarajevo area, with estrogen deficiency in their menstrual history. The controled clinical trials were conducted. Two groups were formed (based on bone mineral density values, according to the WHO criteria). The examination group included 50 women who had osteoporosis, while the control group included 50 women without osteoporosis (osteopenia, normal bone mineral density). The lumbar spine and proximal femur bone mineral density was measured by Dual-Energy X-ray Absorptiometry using Hologic QDR-4000 scanner. Coffee drinking habits were assessed for each subject.

The women who met the following criteria were included in the study: postmenopausal women with estrogen deficiency in menstrual history (fewer than 30 years menstruation, menopause before age of 45 years), women aged 50-65 years, women who live in the Sarajevo area, women with osteoporosis, women without osteoporosis (osteopenia or normal bone mineral density), women who do not use hormone replacement therapy. The exclusion criteria were postmenopausal women without estrogen deficiency in menstrual history, women younger than 
50 and older than 65 years, women who do not live in the Sarajevo area, women who are not postmenopausal, women who use hormone replacement therapy, women who have a disease that can cause osteoporosis, women who use drugs that may cause osteoporosis.

\section{Statistical analysis}

Statistical significance between examination and control group in intake of coffee was tested by Student's t-test. The coefficient of linear correlation between intake of coffee and bone mineral density was calculated. P values less than 0.05 was considered as statistically significant. Data is presented in graphical and tabular forms.

\section{RESULTS}

The average age of women with estrogen deficiency in their menstrual history in the examination group was 58.48 years, and in the control group was 57.30 years (Figure 1). There was no statistically significant differences between these two groups, $\mathrm{t}=1.169$.

The average daily intake of coffee in women with estrogen deficiency in menstrual history was $267.6 \mathrm{ml}$ in the examination group and in the control group $111.6 \mathrm{ml}$ (Figure 2). The difference in the average daily intake of coffee between the two groups was statistically significant, $t=8.697$; $\mathrm{p}<0.001$.

The coefficient of linear correlation between $\mathrm{T}$ scores and the average daily intake of coffee among women with estrogen deficiency in menstrual history in the examination group was statistically significant, $\mathrm{r}=-0.491 ; \mathrm{p}<0.01$. The coefficient of linear correlation between $\mathrm{T}$ scores (Table 1 ) and the daily intake of coffee among women with estrogen deficiency in menstrual history in the control group was statistically significant, $r=-0.356 ; \mathrm{p}<0.05$.

\section{DISCUSSION}

The peak bone mass in the young can be increased and the rate of bone loss in the elderly possibly be reduced by dietary manipulation, which would be important and beneficial in the prevention of osteoporosis (15).

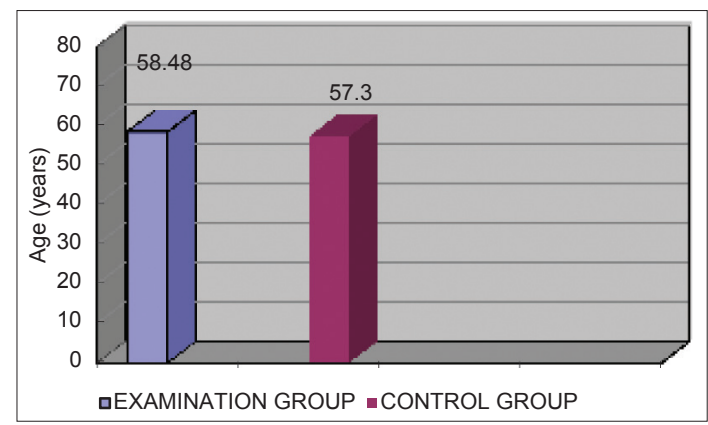

FIGURE 1. The average age of women with estrogen deficiency in menstrual history $\mathrm{t}=1.169$; no statistically significant.

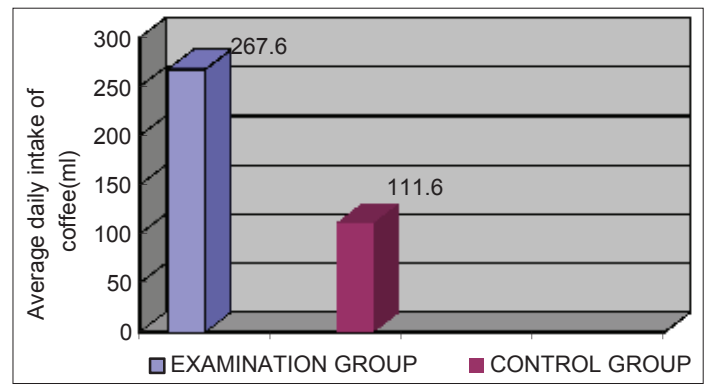

FIGURE 2. The average daily intake of coffee in women with estrogen deficiency in menstrual history, $p<0.001$.

TABLE 1. The coefficient of linear correlation between $T$ scores and the daily intake of coffee among women with estrogen deficiency in menstrual history

\begin{tabular}{lcc}
\hline Parameters & Examination group & Control group \\
\hline Coefficient of & $r=-0.491$ & $r=-0.356$ \\
linear correlation & $p<0.01$ & $p<0.05$ \\
\hline
\end{tabular}

Coffee, a beverage used worldwide, includes a wide array of components that can have potential implication on health (16). Results of the studies on influence of coffee consumption on calcium metabolism, bone mineral density and fracture risk are contradicting. (6-8, 17-22). Potential of coffee intake as an osteoporosis risk factor is under debate (16). Lloyd T. et al. found no association between dietary caffeine intake and total body or femoral neck bone density or bone mass and found no associations between caffeine consumption and longitudinal changes in total body or femoral neck bone measurements (with and without statistical adjustment for calcium intake) (17). In the study of Choi EJ et al. coffee consumption showed no 
significant association with bone mineral density of either femoral neck or lumbar spine in Korean premenopausal women (18). Ilich JZ et al. found that caffeine is negatively associated with bone mineral density of different skeletal sites in elderly women (19). Hallström H. et al. studied the relation between coffee intake and bone mineral density, taking into account, genotypes for cytochrome P450 1A2 (CYP1A2) associated with metabolism of caffeine. Men consuming 4 cups of coffee or more per day had $4 \%$ lower bone mineral density at the proximal femur compared with low or non-consumers of coffee. This difference was not present in women. High consumers of coffee with $\mathrm{C} / \mathrm{C}$ genotype, rapid metabolism of caffeine, had lower bone mineral density than slow metabolizers ( $\mathrm{T} / \mathrm{T}$ and $\mathrm{C} / \mathrm{T}$ genotypes). Calcium intake did not modify the relation between coffee and bone mineral density (20). In their study Tavani A. et al. found no association between hip fractures among women and consumption of regular or decaffeinated coffee, tea, and cola (21). Hallstrom $\mathrm{H}$. et al. found that a high coffee consumption significantly increased the risk of osteoporotic fractures. The results of the study indicate that a daily intake of $330 \mathrm{mg}$ of caffeine, equivalent to 4 cups $(600 \mathrm{ml})$ of coffee, or more, may be associated with a modestly increased risk of osteoporotic fractures, especially in women with a low intake of calcium (22).

Data from animal studies are also inconsistent $(9,10)$. In animal studies the influence of individual constituents of coffee on bone tissue was examined $(23,24)$. The aim of Folwarczna J. et al. study was to investigate the effects of trigonelline, an alkaloid present in coffee, on bone mechanical properties of rats with normal estrogen level and estrogen deficiency. Administration of trigonelline did not affect the bone turnover markers, bone mineralization and mechanical properties of the tibial metaphysis, femoral diaphysis, and femoral neck in non-ovariectomized rats, but it worsened the mineralization and mechanical properties of cancellous bone in ovariectomized rats (estrogen-deficient rats) (23). The results of Folwarczna J. et al. study showed that caffeine has favorably affected on the skeletal system of ovariectomized rats, slightly inhibiting the development of bone changes induced by estrogen deficiency. Study found no significant caffeine effects on the bone in non-ovariectomized rats (normal estrogen levels) (24).

In this study influence of coffee consumption on bone mineral density in postmenopausal women, aged 50-65 years living in Sarajevo area with estrogen deficiency in their menstrual history was examined. The difference in the average daily intake of coffee between the group of women with osteoporosis and group of women without osteoporosis was statistically significant $(\mathrm{p}<0.001)$. The coefficient of linear correlation between $\mathrm{T}$ scores and the average daily intake of coffee was statistically significant in both, group of women with osteoporosis $(\mathrm{p}<0.01)$ and group of women without osteoporosis $(p<0.05)$. Results of this study showed that intake of coffee has an impact on bone mineral density in postmenopausal women, aged 50-65 years living in the Sarajevo area, with estrogen deficiency in their menstrual history. The effect of coffee on bone mineral density was dose-dependent. The average amount of consumed coffee in women with osteoporosis was $267.7 \mathrm{ml}$, and in women without osteoporosis $116.6 \mathrm{ml}$.

\section{CONCLUSION}

This study indicates that coffee consumption is a risk factor for osteoporosis in postmenopausal women, aged 50-65 years living in Sarajevo area, with estrogen deficiency in their menstrual history. It was shown that the effects of coffee on bone mineral density are dose-dependent. Based on the results of this research, it recommended that daily consumption of coffee be limited in order to preserve bone health of postmenopausal women with estrogen deficiency in their menstrual history (the average amount of consumed coffee in women without osteoporosis was $116.6 \mathrm{ml}$ ).

\section{CONFLICT OF INTEREST}

The authors declare that they have no competing interests.

\section{REFERENCES}

1. Clarke BL, Khosla S. Female reproductive system and bone. Estrogen increase bone formation and decrease loss of bone mass. Arch Biochem Biophys. 2010 Nov 1;503(1):118-28. http://dx.doi.org/10.1016/j. abb.2010.07.006. 
2. Nguyen TV, Jones G, Sambrook PN, White CP, Kelly PJ, Eisman JA. Effects of estrogen exposure and reproductive factors on bone mineral density and osteoporotic fractures. J Clin Endocrinol Metab. 1995 Sep;80(9):2709-14.

3. Kurtoglu-Aksoy N, Akhan SE, Bastu E, Gungor-Ugurlucan F, Telci A, lyibozkurt AC, Topuz S. Implications of premature ovarian failure on bone turnover markers and bone mineral density. Clin Exp Obstet Gynecol. 2014;41(2):149-53.

4. Gennari L, Merlotti D, De Paola V, Calabrò A, Becherini L, Martini G, Nuti R. Estrogen Receptor Gene Polymorphisms and the Genetics of Osteoporosis: A HuGE Review Am. J. Epidemiol. (2005)161 (4): 307-320. http//dx.doi.org/10.1093/aje/kwi055.

5. Wierzejska R. Caffeine - common ingredient in a diet and its influence on human health. Rocz Panstw Zakl Hig. 2012;63(2):141-7.

6. Hasling C, Søndergaard K, Charles P, Mosekilde L. Calcium metabolism in postmenopausal osteoporotic women is determined by dietary calcium and coffee intake. J Nutr. 1992 May;122(5):1119-26.

7. Barger-Lux MJ, Heaney RP. Caffeine and the calcium economy revisited. Osteoporos Int. 1995 Mar;5(2):97-102. http://dx.doi.org/10.1007/BF01623310.

8. Heaney RP. Effects of caffeine on bone and the calcium economy. Food Chem Toxicol. 2002 Sep;40(9):1263-70. http://dx.doi.org/10.1016/ S0278-6915(02)00094-7.

9. Lacerda SA, Matuoka RI, Macedo RM, Petenusci SO, Campos AA, Brentegani LG. Bone quality associated with daily intake of coffee: a biochemical, radiographic and histometric study. Braz Dent J. 2010;21(3):199204. http//dx.doi.org/10.1590/S0103-64402010000300004.

10. Sakamoto W, Nishihira J, Fujie K, lizuka T, Handa H, Ozaki M, Yukawa S. Effect of coffee consumption on bone metabolism. Bone. 2001 Mar;28(3):332-6. http//dx.doi.org/10.1016/S8756-3282(00)00444-0.

11. Rapuri PB, Gallagher JC, Kinyamu HK, Ryschon KL. Caffeine intake increases the rate of bone loss in elderly women and interacts with vitamin D receptor genotypes. Am J Clin Nutr. 2001 Nov;74(5):694-700.

12. Tsuang YH, Sun JS, Chen LT, Sun SC, Chen SC. Direct effects of caffeine on osteoblastic cells metabolism the possible causal effect of caffeine on the formation of osteoporosis. J Orthop Surg Res. 2006 Oct 7;1:7. http:// dx.doi.org/10.1186/1749-799X-1-7.

13. Goto A, Song Y, Chen BH, Manson JE, Buring JE, Liu S. Coffee and caffeine consumption in relation to sex hormone-binding globulin and risk of type 2 diabetes in postmenopausal women. Diabetes. 2011 Jan;60(1):269-75. http://dx.doi.org/10.2337/db10-1193.
14. Wedick NM, Mantzoros CS, Ding EL, Brennan AM, Rosner B, Rimm EB, Hu FB, van Dam RM. The effects of caffeinated and decaffeinated coffee on sex hormone-binding globulin and endogenous sex hormone levels: a randomized controlled trial. Nutr J. 2012 Oct 19;1186. http//dx.doi. org/10.1186/1475-2891-11-86.

15. Wang $\mathrm{P}$, Zhang $\mathrm{H}$. Review of dietary risk factors for osteoporosis. Wei Sheng Yan Jiu. 2003 Jan;32(1):81-3.

16. Cano-Marquina A, Tarín JJ, Cano A. The impact of coffee on health. Maturitas. 2013 May;75(1):7-21. http://dx.doi.org/10.1016/j. maturitas.2013.02.002.

17. Lloyd T, Rollings N, Eggli DF, Kieselhorst K, Chinchilli VM. Dietary caffeine intake and bone status of postmenopausal women Am J Clin Nutr. 1997 Jun;65(6):1826-30.

18. Choi EJ, Kim KH, Koh YJ, Lee JS, Lee DR, Park SM. Coffee consumption and bone mineral density in korean premenopausal women. Korean J Fam Med. 2014 Jan;35(1):11-8. http://dx.doi.org/10.4082/kjfm.2014.35.1.11.

19. Ilich JZ, Brownbill RA, Tamborini L, Crncevic-Orlic Z. To drink or not to drink: how are alcohol, caffeine and past smoking related to bone mineral density in elderly women? J Am Coll Nutr. 2002 Dec;21(6):536-44. http:// dx.doi.org/10.1080/07315724.2002.10719252.

20. Hallström H, Melhus H, Glynn A, Lind L, Syvänen AC, Michaëlsson K. Coffee consumption and CYP1A2 genotype in relation to bone mineral density of the proximal femur in elderly men and women: a cohort study. Nutr Metab (Lond). 2010 Feb 22;7:12. http://dx.doi.org/10.1186/1743-7075-7-12.

21. Tavani A, Negri E, La Vecchia C. Coffee intake and risk of hip fracture in women in northern Italy. Prev Med. $1995 \mathrm{Jul} ; 24(4): 396-400$. http://dx.doi. org/10.1006/pmed.1995.1064.

22. Hallström H, Wolk A, Glynn A, Michaëlsson K. Coffee, tea and caffeine consumption in relation to osteoporotic fracture risk in a cohort of Swedish women. Osteoporos Int. 2006;17(7):1055-64. http://dx.doi.org/10.1007/ s00198-006-0109-y.

23. Folwarczna J, Zych M, Nowińska B, Pytlik M, Janas A. Unfavorable effect of trigonelline, an alkaloid present in coffee and fenugreek, on bone mechanical properties in estrogen-deficient rats. Mol Nutr Food Res. 2014 Jul;58(7):1457-64. http://dx.doi.org/10.1002/mnfr.201300936.

24. Folwarczna J, Pytlik M, Zych M, Cegieła U, Kaczmarczyk-Sedlak I, Nowińska B, Sliwiński L. Favorable effect of moderate dose caffeine on the skeletal system in ovariectomized rats. Mol Nutr Food Res. 2013 Oct:57(10):1772-84. 